\title{
Conducting an In-depth Interview ${ }^{1}$
}

\author{
Lisa A. Guion, David C. Diehl, and Debra McDonald ${ }^{2}$
}

In-depth interviews are a useful qualitative data collection technique that can be used for a variety of purposes, including needs assessment, program refinement, issue identification, and strategic planning. In-depth interviews are most appropriate for situations in which you want to ask open-ended questions that elicit depth of information from relatively few people (as opposed to surveys, which tend to be more quantitative and are conducted with larger numbers of people). This paper provides a brief introduction to in-depth interviewing as a tool for collecting rich information that can inform program development and evaluation.

\section{What is an In-depth Interview?}

In-depth, qualitative interviews are excellent tools to use in planning and evaluating Extension programs because they use an open-ended, discovery-oriented method, which allows the interviewer to deeply explore the respondent's feelings and perspectives on a subject. This results in rich background information that can shape further questions relevant to the topic. The key characteristics of in-depth interviews are the following:

- Open-ended Questions. Questions need to be worded so that respondents expound on the topic, not just answer "yes" or "no." Many open-ended questions begin with "why" or "how," which gives respondents freedom to answer the questions using their own words.
- Semi-structured Format. Although it is important to pre-plan the key questions, the interview should also be conversational, with questions flowing from previous responses when possible. For example, if an interviewee remarks that "The elections are approaching," an appropriate response would be, "How do you feel about the candidates involved?"

- Seek Understanding and Interpretation. It is important to use active listening skills to reflect upon what the speaker is saying. The interviewer should try to interpret what is being said and should seek clarity and understanding throughout the interview.

- Recording Responses. The responses are typically audio-recorded and complemented with written notes (i.e., field notes) by the interviewer. Written notes include observations of both verbal and non-verbal behaviors as they occur, and immediate personal reflections about the interview.

In sum, in-depth interviews involve not only asking questions, but systematically recording and documenting the responses to probe for deeper meaning and understanding.

\section{Skills and Attributes of the Interviewer}

A skilled qualitative interviewer should be:

1. This document is FCS6012, one of a series of the Department of Family, Youth and Community Sciences, Florida Cooperative Extension Service, Institute of Food and Agricultural Sciences, University of Florida. Original publication date October 2001. Revised January 2006; August 2011. Original written by Lisa A. Guion, former faculty member, revised by David C. Diehl and Debra McDonald. Visit the EDIS website at http://edis.ifas.ufl.edu.

2. Lisa A Guion, former faculty member; David C. Diehl, assistant professor; Debra McDonald, project coordinator; Department of Family, Youth and Community Sciences; Florida Cooperative Extension Service; Institute of Food and Agricultural Sciences; University of Florida; Gainesville, FL 32611. 
1. Open-minded. Judgment or criticism can act as barriers to communication, so it is important to maintain openness during the interview process. If interviewees perceive that they are being judged or evaluated, then they are less likely to openly share their opinions. Any conclusions that need to be made can be written in a journal after the interview is over.

2. Flexible and responsive. Human interactions are complex and people's responses to questions are rarely predictable, so good interviewers can think on their feet, respond to challenges, and make sure that the core purpose is being served.

3. Patient. Allow the respondent to speak freely and open up at a pace that is personally comfortable.

4. Observant. Good interviewers are observant, picking up subtle cues such as facial expressions, body language, and tone of voice.

5. A good listener. A good listener is one who listens actively, using strategies such as:

- Attending fully to what the speaker is saying by focusing wholly on what is being said. Active listening requires the listener to give full attention to the speaker until either the message has been received or the speaker has finished speaking.

- Paraphrasing what the speaker is saying to confirm to the speaker that the listener is actually listening and that the message conveyed is the message received. Paraphrasing also has the added benefit of forcing a speaker to focus wholly on the conversation, thus limiting distractions.

- Reflecting back to the speaker the emotions inherent in the message. By paying attention to tone and emotional content, the interviewer can gain a greater understanding of the messages being delivered.

Although active listening sounds easy, it can take a lot of practice to learn. Thus, prior to conducting an in-depth interview, it is important to practice active listening on a friend or colleague. Begin by instructing a friend to talk about a topic of interest and practice your active listening strategies during the conversation. Afterward, ask for feedback and continue with different topics until active listening becomes a natural way of interacting.

\section{Conducting an In-depth Interview}

Kvale (1996) details seven stages of conducting in-depth interviews: thematizing, designing, interviewing, transcribing, analyzing, verifying, and reporting.

Stage 1: Thematizing. In this stage, it is important to clarify the purpose of the interviews. The first question is whether you are using the interview for program planning. For example, you may want to use in-depth interviews as part of the needs assessment process by interviewing key members of the target audience and/or influential stakeholders. Or, your desire may be to use in-depth interviewing to complement other methods of evaluating your program. Once you have decided on your general purpose, then you can pinpoint the key information you want to gather through the in-depth interview process.

Stage 2: Designing. After you determine what you want to know, you should design a way to elicit this information through the interview process. An interview guide that includes the key topics and questions will be your formalized plan for collecting information. See "Qualitative Research Methods: A Data Collector's Field Guide" in the References and Resources section for a sample interview guide.

The interview guide should be designed to help the interviewer focus on topics that are important to explore, maintain consistency across interviews with different respondents, and stay on track during the interview process.

The three basic parts of the interview guide are as follows:

1. The facesheet, which is used to record the time, date, and place of the interview, special conditions or circumstances that may affect the interview, and demographic information about the respondent being interviewed

2. The interview questions, which are placed on the left side of the page, along with a blank space on the right side of the page for written observations

3. The post-interview comment sheet, which is a place to write notes after the interview; these notes should include feelings, interpretations, and other comments that arose during the interview

Stage 3: Interviewing. In the beginning of the interview, it is important to make introductions, explain the purpose of the study, and put the respondent at ease. If you plan to audio record the session, obtain the respondent's permission and test the equipment to make sure it is working 
properly. Your main responsibility is to listen and observe as you guide the respondent through a conversation until all of the important issues on the interview guide are explored. Please see the earlier section on "Skills and Attributes of the Interviewer" for guidance on how to conduct good interviews.

Stage 4: Transcribing. Transcribing involves creating a verbatim text of each interview by writing out each question and response using the audio recording. The interviewer's side notes should also be included in the transcription, and properly labeled in a separate column or category.

Stage 5: Analyzing. Analyzing involves re-reading the interview transcripts to identify themes emerging from the respondents' answers. You can use your topics and questions to organize your analysis, in essence synthesizing the answers to the questions you have proposed. If the interviews raise more questions than they answer, then more interviews may be necessary to properly examine the issue at hand.

Stage 6: Verifying. Verifying involves checking the credibility of the information gathered and a method called triangulation is commonly used to achieve this purpose. Triangulation involves using multiple perspectives to interpret a single set of information. For example, a study that uses triangulation to examine the outcomes of a Parenting Communication class would require researchers to interview at least three groups of participants: parents, children, and other household members. When each participant says the same thing in the interviews, then the information that results is considered valid.

A simpler way to use triangulation in a study would be to have two colleagues read and analyze the same set of transcripts, and then compare notes. If the notes agree, then the information is credible.

Stage 7: Reporting. Finally, it is important to share results from the in-depth interviews with internal and external stakeholders through a written or oral report; these reports should describe not only the results, but how the results will shape future work. When respondents see the information being used, they are more likely to participate in future data collection efforts.

\section{Summary}

When you want to gather rich data about Extension programs, in-depth interviews can be a valuable tool to guide your work. There really is no substitute for face-to-face communication, and in-depth interviews provide the structure to ensure that these conversations are both well-organized and well-suited to your purpose. While time-consuming and labor-intensive, in-depth interviews can provide rich data to inform Extension programming.

\section{References and Resources}

Boyce, C. \& Neale, P. (2006). Conducting In-depth interviews: A Guide for Designing and Conducting In-depth Interviews for Evaluation Input. Online. http://www. pathfind.org/site/DocServer/m_e_tool_series_indepth_interviews.pdf? docID $=6301$

Burley-Allen, M. (1995). Listening: The Forgotten Skill (A self-teaching guide). Hoboken, NJ: John Wiley \& Sons.

Donoghue, P.J. \& Siegel, M.E. (2005). Are You Really Listening? Keys to Successful Communication. Notre Dame, IN: Sorin Books.

Friesen, B. (2010). Designing and Conducting Your First Interview Project. San Francisco: Jossey-Bass.

Kvale, S. (1996). Interviews: An Introduction to Qualitative Research Interviewing. Thousand Oaks, CA: Sage.

Lincoln, Y.S., \& Guba, E.G. (1985). Naturalistic Inquiry. Newbury Park, CA: Sage Publications.

Longsfield, Kim (2004). In-depth Interviews. Online. http:// www.aidsmark.org/ipc_en/pdf/manual/14_Research-

Toolkit-Ch6-In-Depth-Interviews.pdf

Mack, N., Woodsong, C., MacQueen, K., Guest, G., \& Namey, E. (2005). Qualitative Research Methods: A Data Collector's Field Guide. Online. http://www.fhi.org/en/RH/ Pubs/booksReports/QRM_datacoll.htm

Rubin, H. J. \& Rubin, I. S. (2004). Qualitative Interviewing: The Art of Hearing Data (2nd ed.). Thousand Oaks, CA: Sage Publications.

Wertz, F., Charmaz, K., McMullen, L., Josselson, R., Anderson, R., \& McSpadden, E. (2011). Five Ways of Doing Qualitative Research. New York: Guilford Press. 